\title{
Numerical modeling of the thermal contact in metal forming processes
}

\author{
J. M. P. Martins ${ }^{1}$ - D. M. Neto ${ }^{1}$ - J. L. Alves ${ }^{2}$ - M. C. Oliveira ${ }^{1}$ - L. F. Menezes ${ }^{1}$
}

Received: 3 November 2015 / Accepted: 29 February 2016 / Published online: 12 March 2016

(C) Springer-Verlag London 2016

\begin{abstract}
Heat flow across the interface of solid bodies in contact is an important aspect in several engineering applications. This work presents a finite element model for the analysis of thermal contact, which takes into account the effect of contact pressure and gap dimension in the heat flow across the interface between two bodies. Additionally, the frictional heat generation is also addressed, which is dictated by the contact forces predicted by the mechanical problem. The frictional contact problem and thermal problem are formulated in the frame of the finite element method. A new law is proposed to define the interfacial heat transfer coefficient (IHTC) as a function of the contact pressure and gap distance, enabling a smooth transition between two contact status (gap and contact). The staggered scheme used as coupling strategy to solve the thermomechanical problem is briefly presented. Four numerical examples are
\end{abstract}

D. M. Neto

diogo.neto@dem.uc.pt

J. M. P. Martins

joao.pmartins@dem.uc.pt

J. L. Alves

jlalves@dem.uminho.pt

M. C. Oliveira

marta.oliveira@dem.uc.pt

L. F. Menezes

luis.menezes@dem.uc.pt

1 CEMUC, Department of Mechanical Engineering, University of Coimbra, polo II, Rua Luís Reis Santos, Pinhal de Marrocos, 3030-788 Coimbra, Portugal

2 CMEMS, Centre for MicroElectroMechanical Systems Research, University of Minho, Campus de Azurm, 4800-058 Guimares, Portugal presented to validate the finite element model and highlight the importance of the proposed law on the predicted temperature.

Keywords Thermal contact - Interfacial heat transfer coefficient (IHTC) - Frictional heat generation · Finite element method (FEM) · Coupling strategy $\cdot$ Metal forming

\section{Introduction}

The heat flow across the interface between two contacting bodies plays an important role in many engineering applications, such as the automotive [52], microelectronics [54], metalworking [37], and gas turbine industries [17]. The heat flow across contacting interfaces is commonly quantified by the interfacial heat transfer coefficient (IHTC), which is the inverse of the resistance to heat flow [28]. This resistance is the cause of temperature discontinuity at the interface between the bodies. Three different methods can be used to calculate the IHTC from experimentally measured temperatures [55], which are: the heat balance method, the Beck's method [9], and the finite element analysis based optimization method (FEA method). Zhao et al. [55] have compared these three methods using a hot stamping experimental setup to determine the IHTC evolution during the process. They concluded that the Beck's method presents the most accurate results, followed by the heat balance method and finally, the FEA method, which has the less accurate results, due to the fact that the model used only provides a constant value for the IHTC evolution. IHTC evaluation studies have been increasing during the last few years, in several areas of industry. Recently, Dureja et al. [16] have proposed a new experimental set-up, for the IHTC determination between pressure and calandria tubes from a heavy water reactor. 
They highlighted a linear increase of the IHTC with the contact pressure up to $10 \mathrm{MPa}$. Akar et al. [3] have also investigated the IHTC evolution during the casting process, because the IHTC is an important factor for reliable results on the numerical simulation of casting processes. The IHTC also plays a crucial role in hot/warm sheet metal forming processes, since the heat exchanges on the interface of the sheet are important for the temperature control and, consequently, the mechanical properties of the final part [21, 29, 33]. In fact, the numerical modeling of the interfacial heat transfer requires the prior determination of the IHTC [27]. Thus, the accurate evaluation of this parameter is essential for the thermal and mechanical analysis of any system. Nevertheless, the modeling of the heat transfer across a contact interface is one of the well-known problems in the numerical simulation of thermal boundary conditions. Typically, the IHTC is assumed constant in the numerical modeling, although it is known that it is affected by several factors, such as, the surface roughness and flatness, contact pressure, mechanical properties of the contacting surfaces and gap distance $[26,45]$. The roughness and flatness of the contact surface have a significant effect on the IHTC, which decreases with the increase in surface flatness and decrease in roughness [11]. Indeed, the real contact area is a very small fraction of the nominal contact area ( $2 \%$ for metallic contact). The real contact occurs only in certain discrete points, at the top of asperities [28]. The contact pressure has a close connection with the real contact area, since the deformation of the contacting asperities induced by the contact pressure increases the real contact area and, consequently, the IHTC value. The effects of the contact pressure during the hot forging process were investigated by Bai et al. [5]. They reported an exponential increase of the IHTC up to $100 \mathrm{MPa}$, followed by a slightly increase for higher pressures. Chang et al. [13] measured the IHTC during the hot stamping of an advanced high strength steel, obtaining the same trend for the IHTC with the contact pressure, proposing a power law to fit the experimental data. Since the deformation of the asperities is directly defined by the hardness of the contacting surfaces, it is greater for soft materials than for hard ones. Therefore, soft materials present a larger effective contact surface area and, consequently, higher values of the IHTC than hard materials. There are a number of empirical and semi-empirical correlations for the determination of the IHTC (or contact condutance) in function of the roughness, contact pressure, and the hardness of the material, for example the Yovanovich's plastic model [53] and the Mikic's plastic deformation model [34]. However, this models tend to overestimate the IHTC value. $\mathrm{Xu}$ and $\mathrm{Xu}$ [50] pointed a possible reason for that, which is the use of a constant hardness value in the calculation. In fact, the hardness varies with the temperature, but it is difficult to evaluate this evolution [31].
The heat transfer across the contact interface occurs by conduction through asperities in contact, convection through the fluid inside the gap, and by radiation across the gap [47]. The radiation can be negligible for temperatures lower than $300^{\circ} \mathrm{C}$ [28]. The gap fluid conductance is less efficient than the conduction through asperities. Thus, the increasing of the gap separating the contact surfaces decreases the IHTC value. In fact, Merklein et al. [32] investigated the influence of the gap distance between two contacting surfaces on the IHTC in hot stamping, concluding that the increase of the gap yields a IHTC decrease, independent of the temperature of the contacting surfaces. For the worst case reported, the IHTC value has decayed approximately $240 \mathrm{~W} / \mathrm{m}^{2} \mathrm{~K}$, between a gap distance of 1 to $1.5 \mathrm{~mm}$, and only $40 \mathrm{~W} / \mathrm{m}^{2} \mathrm{~K}$, between a gap distance of 1.5 to $2 \mathrm{~mm}$.

The sliding contact between solids generates energy, which originates an increase of temperature at the interface and affects the mechanical behavior of the system. The conversion of mechanical energy into frictional heating is usually assumed around 80-100\% [6], while the remaining energy is dissipated in abrasive wear and changes of surface topography. The amount of factors involved in the frictional heating (contacting materials, sliding velocity, normal pressure, roughness, temperature, etc.) increases significantly the complexity of this phenomenon [10]. Nevertheless, an accurate prediction of the temperature rise due to frictional heating is crucial for thermal stress analysis and thermal wear modeling [7, 22]. Typically, the heat generated is modeled based on the applied load, sliding velocity, and friction coefficient [15]. In the numerical modeling, the friction coefficient is commonly assumed as constant, although it depends on the roughness of the contacting surfaces, lubrication conditions, temperature of the surfaces, applied load, and plastic deformation [14, 24]. Besides this assumption, the total amount of heat generated at the interface has to be distributed between the contacting bodies, requiring the definition of a coefficient of partition, which depends on several factors as shown in tribological studies [7, 44]. Nevertheless, it is usually assumed equally partitioned between the two bodies.

The finite element analysis of thermomechanical problems allows to understand the thermal effects occurring at the contact interface of two bodies, which is of crucial interest for industrial applications [2, 38, 41, 48, 49]. Thus, the improvement of the actual algorithms is essential for the development of the numerical simulation, namely in the field of sheet metal forming. In fact, the concept of lightweight vehicles led to the introduction of new materials, such as advanced high strength steels [23], which contributed for the accentuated role of frictional heating in conventional cold sheet metal forming [42] and the need to develop temperature supported sheet metal forming 
processes, such as hot and warm sheet metal forming [20, $25,46]$. Hence, this work presents an algorithm able to model the conductive heat flow across the contact interface between a deformable body and a rigid obstacle. The proposed model takes into account both the contact pressure and the gap distance in the evaluation of the IHTC. Besides, the heat generation at the interface due to frictional contact is also predicted by the model.

The outline of the paper is the following. Section 2 is dedicated to the formulation of contact and heat transfer problems and to the description of the global thermomechanical coupled algorithm, with emphasis on the thermal problem. In Section 3, four numerical examples are used to validate the proposed model, which highlights the importance of an accurate modeling of the heat exchanges on the interface.

\section{Finite element formulation}

\subsection{Frictional contact}

This section contains the formulation of the frictional contact problem between a deformable body involving large deformation and a rigid obstacle with arbitrary shape, as shown in Fig. 1. The domain occupied by the deformable body $\mathcal{B}$ in the current configuration is represented by the open set $\Omega$. The closure of the open set denotes the boundary surface $\gamma$, which is divided into three disjoint open sets: $\gamma=$ $\gamma_{\mathrm{u}} \cup \gamma_{\sigma} \cup \gamma_{\mathrm{c}}$ representing the Dirichlet, Neumann, and contact portions, respectively. The body is subject to prescribed displacements $\overline{\mathbf{u}}$ on the Dirichlet region of the boundary $\gamma_{\mathrm{u}}$, prescribed tractions $\overline{\mathbf{t}}$ on the Neumann region of the boundary $\gamma_{\sigma}$ and to contact constraints on the remaining region $\gamma_{\mathrm{c}}$.

Assuming quasi-static response (no inertia terms), the boundary value problem formulated in the current configuration is governed by the following balance equations:

$$
\begin{cases}\nabla \cdot \sigma+\mathbf{b}=0 & \text { in } \Omega, \\ \mathbf{t}=\overline{\mathbf{t}} & \text { at } \gamma_{\sigma}, \\ \mathbf{u}=\overline{\mathbf{u}} & \text { at } \gamma_{\mathrm{u}},\end{cases}
$$
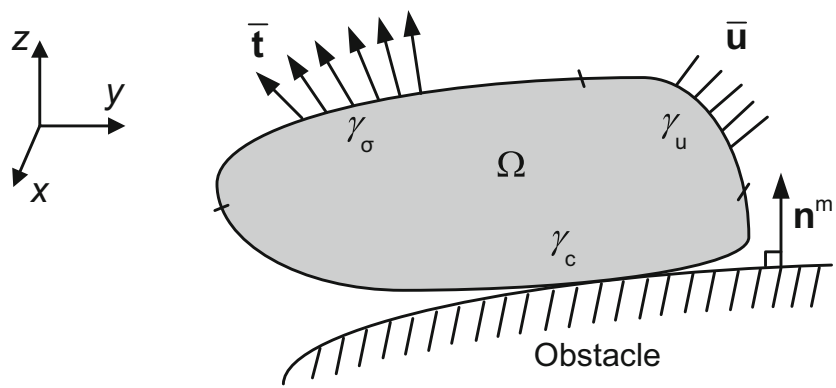

Fig. 1 Deformable body in contact with a rigid obstacle and respective boundary conditions where $\sigma$ is the Cauchy stress tensor and $\mathbf{b}$ denotes the body forces applied in the body volume. In order to include constraints resulting from the frictional contact between the deformable body and the rigid obstacle, the kinematic and static contact variables are defined. The contact interaction between the deformable body and the rigid obstacle is expressed by the gap function and the tangential relative sliding. The normal gap is evaluated in each slave node, where the counterpart point on the master surface is evaluated by means of the projection of the slave node on the master surface. Considering a slave node $\mathbf{x}^{\mathrm{s}}$ of the deformable body, the normal gap function is defined as:

$g_{\mathrm{n}}\left(\mathbf{x}^{\mathrm{s}}\right)=\left(\mathbf{x}^{\mathrm{s}}-\overline{\mathbf{x}}^{\mathrm{m}}\right) \cdot \overline{\mathbf{n}}^{\mathrm{m}}$,

where $\overline{\mathbf{x}}^{\mathrm{m}}$ indicates the closest point from the slave onto the master surface and $\overline{\mathbf{n}}^{\mathrm{m}}$ is the outer normal vector to the master surface at the projection point (Fig. 1). This definition of the normal gap function establishes that the function value is positive when the contact is open; otherwise, it will be negative. The tangential sliding of the deformable body over the rigid surface, which is necessary for modeling friction effects, is evaluated through the change of the closest point projection. The tangential slip increment of a slave node on the rigid surface is defined in the incremental form as:

$\mathbf{g}_{\mathrm{t}}=\Delta \bar{\xi}^{\alpha} \overline{\boldsymbol{\tau}}_{\alpha}^{\mathrm{m}}, \quad \alpha=1,2$,

where $\overline{\boldsymbol{\tau}}_{\alpha}^{\mathrm{m}}$ are the covariant tangential basis vectors of the master surface and $\Delta \bar{\xi}^{\alpha}$ denotes the increment of the convective coordinates.

The static variable used to model the frictional contact interactions is the contact traction vector in the current configuration, which is resolved into its normal and tangential components:

$\mathbf{t}=p_{\mathrm{n}} \overline{\mathbf{n}}^{\mathrm{m}}+\mathbf{t}_{\mathrm{t}}$

where $p_{\mathrm{n}}$ is normal contact pressure and $\mathbf{t}_{\mathrm{t}}$ denotes the friction traction. This Cauchy stress vector represents physically the force exerted by the slave node on the master surface. The constraints related with impenetrability and friction conditions are expressed considering relationships between the previously presented kinematic and static variables. The contact traction in the normal and in the tangential directions are coupled with the normal gap and the tangential slip increment, respectively. The unilateral contact condition, which defines the physical requirements of impenetrability and compressive interaction between the bodies, is given by:

$g_{\mathrm{n}} \geq 0, \quad p_{\mathrm{n}} \leq 0, \quad p_{\mathrm{n}} g_{\mathrm{n}}=0$

which must hold for all slave nodes. The relationship between the normal gap and the normal contact pressure is presented in Fig. 2a. The frictional response is formulated 


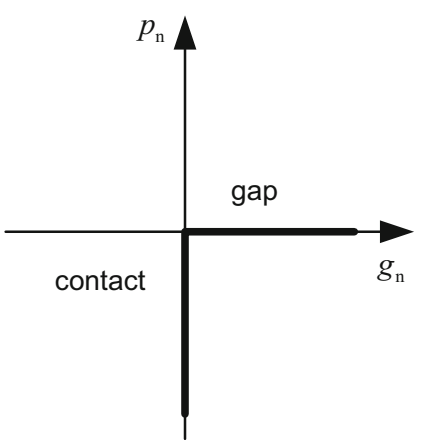

(a)

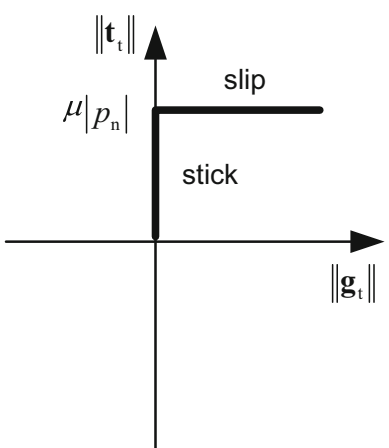

(b)
Fig. 2 Relationship between the normal gap and the normal contact pressure (a) and relationship between the friction force value and the slip increment (b)

using the Coulombs friction law, establishing that the friction force depends on the contact pressure. The constraints imposed by the friction law are described by the following three conditions:

$$
\begin{gathered}
\left\|\mathbf{t}_{\mathrm{t}}\right\|-\mu\left|p_{\mathrm{n}}\right| \leq 0, \\
\left\|\mathbf{t}_{\mathrm{t}}\right\|-\mu\left|p_{\mathrm{n}}\right| \frac{\mathbf{g}_{\mathrm{t}}}{\left\|\mathbf{g}_{\mathrm{t}}\right\|}=0, \\
\left\|\mathbf{g}_{\mathrm{t}}\right\|\left(\left\|\mathbf{t}_{\mathrm{t}}\right\|-\mu\left|p_{\mathrm{n}}\right|\right)=0,
\end{gathered}
$$

where $\mu$ is the friction coefficient. If the value of the friction force has not reached the Coulomb's threshold, the node is not allowed to move in the tangential direction (stick status). On the other hand, when the friction force reaches the Coulomb's limit, the node moves in the tangential direction (slip status). Figure $2 \mathrm{~b}$ shows the relationship between the friction force value and the slip increment.

\subsection{Heat transfer}

This section contains the formulation of the heat transfer problem between a heat conductor body and an isothermal obstacle with arbitrary shape, as shown in Fig. 3. The variational form is also presented, since it is required to

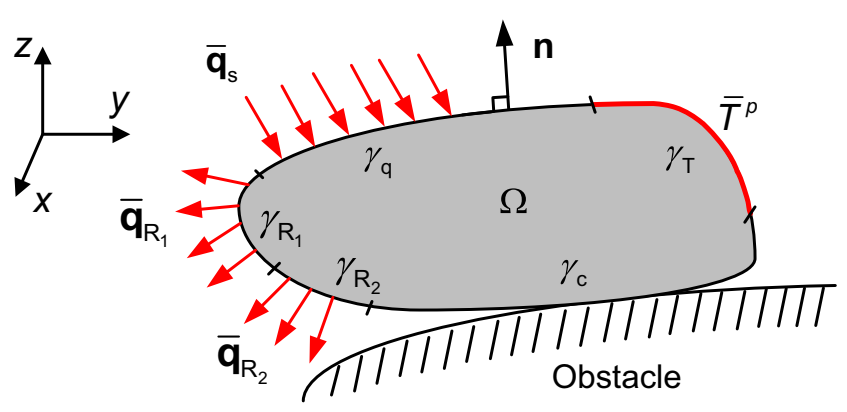

Fig. 3 Heat conductor solid body in contact with an isothermal obstacle with arbitrary shape and respective boundary conditions implement the finite element method, as well as the time integration scheme.

Heat transfer within a solid body $\mathcal{B}$ takes place by conduction, while the heat exchanges occurs in the boundaries surfaces. The differential equation governing the heat transfer within a solid medium, defined by the open set $\Omega$ for the current configuration, can be derived from the first principle of thermodynamics, which combined with the Fourier's heat conduction law, assumes the following form:

$\rho c \frac{\partial T}{\partial t}=\nabla \cdot(\mathbf{k} \cdot \nabla T)+Q, \quad$ in $\Omega$,

where $\rho$ is the density, $c$ is the specific heat of the material, and $\mathbf{k}$ is the thermal conductivity tensor. The term $Q$ is the internal heat generation per unit volume where, e.g., the energy generated by plastic deformation can be included [43].

The transient heat conduction phenomenon is expressed by Eq. 7, which involves a temperature field dependent on the time. Thus, the initial value problem requires an initial condition on the temperature field, defined as $T^{0}$ for the open set $\Omega^{0}$ in the initial configuration. The remaining boundaries conditions are specified on the boundary surface $\gamma$, defined as the closure of the open set $\Omega$. The boundary surface is composed by five disjoint open sets: $\gamma=$ $\gamma_{\mathrm{T}} \cup \gamma_{\mathrm{q}} \cup \gamma_{\mathrm{R}_{1}} \cup \gamma_{\mathrm{R}_{2}} \cup \gamma_{\mathrm{c}}$, corresponding to the Dirichlet, Neumann, Robin, and thermal contact portions, respectively. The Dirichlet, Neumann, and Robin boundary conditions, correspond to a temperature imposed, a constant heat flux and a heat flux dependent on the temperature of the surface, respectively. This conditions can be defined as follow:

$$
\begin{aligned}
T & =\bar{T}^{p}, & & \text { at } \gamma_{\mathrm{T}}, \\
q_{\mathrm{s}} & =(\mathbf{k} \cdot \nabla T) \cdot \overline{\mathbf{n}}=\bar{q}_{\mathrm{s}}, & & \text { at } \gamma_{\mathrm{q}}, \\
q_{\mathrm{R}_{1}} & =(\mathbf{k} \cdot \nabla T) \cdot \overline{\mathbf{n}}=h_{\mathrm{conv}}\left(T-T_{\infty}\right), & & \text { at } \gamma_{\mathrm{R}_{1}}, \\
q_{\mathrm{R}_{2}} & =(\mathbf{k} \cdot \nabla T) \cdot \overline{\mathbf{n}}=h_{\mathrm{rad}}\left(T-T_{\mathrm{r}}\right), & & \text { at } \gamma_{\mathrm{R}_{2}},
\end{aligned}
$$

where $\overline{\mathbf{n}}$ is the outer normal vector to the solid body surface, $T_{\infty}$ is the environment temperature, $h_{\text {conv }}$ is the convection coefficient, and $h_{\text {rad }}$ is the radiation coefficient. The last one is defined as:

$h_{\mathrm{rad}}=\kappa_{\mathrm{r}}\left(T^{2}+T_{\mathrm{r}}^{2}\right)\left(T+T_{\mathrm{r}}\right)$

where $T_{\mathrm{r}}$ is the temperature of a surrounding surface and $\kappa_{\mathrm{r}}$ is a parameter dependent on the emissivity of the body, the Stefan-Boltzman's constant and the view factors.

The mechanical contact between two bodies with distinct temperatures induces a process of interfacial heat transfer between them. The heat exchange on the interface is directly defined by the interfacial heat transfer coefficient (IHTC), which depends on several local variables, as mentioned in Section 1. In the present study, it is assumed as being dependent on the contact pressure $\left(p_{n}\right)$ and on the gap distance 
$\left(g_{n}\right)$, allowing to predict accurately a wide range of contact conditions involved in forming processes. The heat flux on the contact surface $\gamma_{\mathrm{c}}$ is given by:

$q_{\text {int }}=h_{\text {int }}\left(p_{\mathrm{n}}, g_{\mathrm{n}}\right)\left(T-T_{\mathrm{obs}}\right), \quad$ at $\gamma_{\mathrm{c}}$

where $h_{\text {int }}$ is the IHTC and $T$ and $T_{o b s}$ are the surface tem- peratures of the solid body and the isothermal obstacle. The IHTC is modeled with an empirical law, which takes into account the dependence on the contact pressure and on the gap distance, the mathematical function proposed is inspired in the experimental results of the macro-contact analysis [5, $13,32]$, and is expressed by:

$h_{\text {int }}\left(p_{\mathrm{n}}, g_{\mathrm{n}}\right)= \begin{cases}h_{\text {med }}+\left(h_{\text {sup }}-h_{\text {med }}\right)\left(1-\exp \left(m_{1} p_{\mathrm{n}}\right)\right) & \text { if } p_{\mathrm{n}}<0 \wedge g_{\mathrm{n}}=0 \\ h_{\text {inf }}-\left(h_{\text {inf }}-h_{\text {med }}\right) \exp \left(-m_{2} g_{\mathrm{n}}\right) & \text { if } g_{\mathrm{n}} \geq 0 \wedge p_{\mathrm{n}}=0\end{cases}$

where $h_{\text {sup }}$ and $h_{\text {inf }}$ are the upper and lower threshold values for the IHTC. The piecewise definition of the IHTC allows accounting both mechanical contact status (gap and contact). The graphical representation of this function is depicted in Fig. 4, presenting two horizontal asymptotes, corresponding to $h_{\text {sup }}$ and $h_{\text {inf }}$. When the contact pressure tends to infinity (negative), the IHTC is equal to $h_{\text {sup }}$, i.e., the upper threshold value. On the other hand, when the gap distance tends to infinity (positive), the IHTC is equal to $h_{\text {inf }}$, corresponding to the lower threshold value, i.e. the natural convection coefficient value. The parameters $h_{\text {med }}, m_{1}$ and $m_{2}$ allows to control the rate of the increase/decrease of the IHTC. This empirical law is attractive from the numerical point of view because it promotes a smooth transition of the IHTC between the two contact status (gap and contact), while allowing an accurate fitting to the IHTC values determined from experimental temperatures.

The frictional heat generation should be taken into account when the friction is considered in the mechanical contact. Considering the frictional contact problem involving a solid body and an isothermal obstacle, the heat flux due to frictional heat generation at the interface can be expressed as:

$q_{\text {frict }}=\beta\left(\xi \mathbf{t}_{\mathbf{t}} \cdot \dot{\mathbf{g}}_{\mathrm{t}}\right), \quad$ at $\gamma_{\mathrm{c}}$

where $\xi$ represents the fraction of generated energy converted into heat, which is partitioned between the solid body

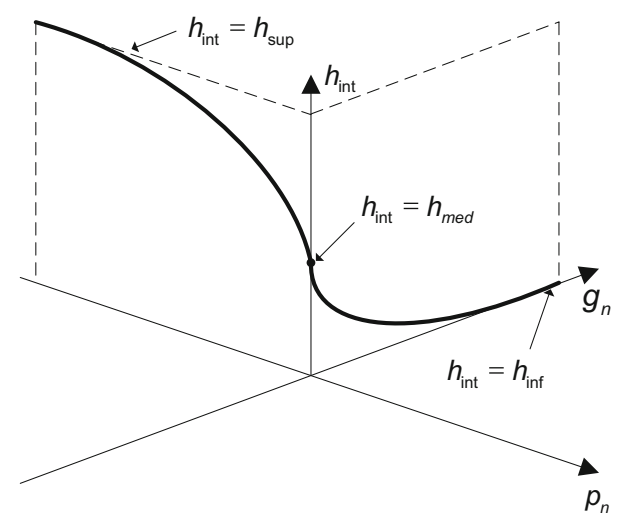

Fig. 4 Interfacial heat transfer coefficient and the isothermal obstacle. Therefore, the parameter $\beta$ defines the total amount of heat dissipated to the solid body. The frictional heat is directly proportional to the friction force $\mathbf{t}_{\mathrm{t}}$ and the increment of tangential slip velocity $\dot{\mathbf{g}}_{\mathrm{t}}$, as highlighted in Eq. 12.

Applying the principle of virtual temperature [8] and proceeding to the decomposition of the domain, the boundary value problem defined in Eq. 7 can be given in the matrix form as:

$\mathbf{C} \dot{\mathbf{T}}+\mathbf{K T}=\mathbf{f}$

where the matrixes and vector are given by:

$\mathbf{C}=\int_{\Omega} \rho c \mathbf{N}^{\mathrm{T}} \mathbf{N} \dot{\mathbf{T}} \mathrm{d} \Omega$

$\mathbf{K}=\int_{\Omega} \mathbf{M}^{\mathrm{T}} \mathbf{k} \mathbf{M T} \mathbf{T} \Omega+\int_{\gamma_{\mathrm{tc}}} h_{\mathrm{int}} \mathbf{N}_{\mathrm{s}}^{\mathrm{T}} \mathbf{N}_{\mathrm{s}} \mathbf{T d} \gamma$

$\mathbf{f}=\int_{\gamma_{\text {tc }}} h_{\text {int }} T_{\text {obs }} \mathbf{N}_{\mathrm{s}}^{\mathrm{T}} \mathrm{d} \gamma+\int_{\gamma_{\text {tc }}} q_{\text {frict }} \mathrm{d} \gamma$

where $\mathbf{N}$ and $\mathbf{N}_{\mathrm{s}}$ are the vectors of the shape functions associated to the volume and surface of the body and $\mathbf{M}=\nabla \mathbf{N}$. The transient heat conduction Eq. 13 is integrated over the time using the generalized trapezoidal method [18], which is a one time step method, given by:

$\mathbf{T}_{t+\Delta t}=\mathbf{T}_{t}+\left[\alpha \dot{\mathbf{T}}_{t+\Delta t}+(1-\alpha) \dot{\mathbf{T}}_{t}\right] \Delta t$

where $t$ is the time instant and $\Delta t$ the time increment. The parameter $\alpha$ can vary between 0 and 1. Depending on the value attributed to this parameter, the generalized trapezoidal method takes the form of different integration methods, namely Euler forward method $(\alpha=0)$, CrankNickolson method $(\alpha=1 / 2)$, Galerkin method $(\alpha=2 / 3)$, and Euler backward method $(\alpha=1)$ [18].

\subsection{Staggered coupling scheme}

The numerical solution of the thermal problem arising in the interface between two bodies requires the resolution of the mechanical problem in order to evaluate the contact forces and relative distances. Thus, the algorithm adopted to perform the thermomechanical coupling is briefly presented. 
The problem is separated into one mechanical problem where the contact forces are evaluate and one thermal problem for the temperature evaluation. The separately treatment of each of these subproblems is completely implicit and is performed recurring to the Newton-Raphson iterative method, to ensure that the thermal and mechanical fields are consistent at the end of each time step. Two types of schemes can be used to perform the coupling between the two problems: (i) a fully coupled scheme, where the two problems are treated simultaneously; (ii) a staggered coupled scheme, where the two problems are treated separately [12]. The former scheme has a better computational efficiency, particularly when the thermal problem is linear [19]. The staggered scheme is adopted in the present study, where the mechanical problem is solved for a previously calculated temperature field, while the thermal problem is solved in the current equilibrium configuration [1, 49].

This algorithm was implemented in DD3IMP in-house finite element code, which has been developed to simulate sheet metal forming processes [30, 40]. The deformation of the body is described by an update Lagrangian formulation, where the region occupied by the deformable body at a given instant $t$ is denoted by configuration $C^{[t]}$. The contact constrains are enforced using an augmented Lagrangian method, where the Lagrangian multiplier vector $(\lambda)$ represents the contact force vector needed to fulfil the frictional constrains [4]. Thus, the nodal displacements (u) and contact forces $(\lambda)$ are evaluated in the mechanical problem, while the temperature field $(\mathbf{T})$, as the new unknown, is evaluated in the thermal problem. The mechanical problem comprises a prediction phase, based on an explicit approach, and a correction phase, based on an implicit approach. Within the explicit approach, an approximated first solution is calculated for the nodal displacements $\mathbf{u}^{[t+\Delta \text {,trial }]}$ and nodal frictional contact forces $\lambda^{[t+\Delta \text {, trial }]}$, for the increment $t+\Delta t$. Then, an $r_{\min }$ strategy is employed to restrict the increment size, in order to improve the convergence rate of the mechanical correction phase, which is based on a fully implicit algorithm of Newton-Raphson type to solve, within a single iterative loop, the non-linearities related with both the mechanical behavior of material and the contact with friction $[36,39,51]$. The resolution of the thermal problem is carried out after achieving the mechanical equilibrium. The solution of the thermal problem uses the updated configuration $C^{[t+\Delta t]}, \mathbf{u}^{[t+\Delta t]}, \lambda^{[t+\Delta t]}$ and the temperature field of the last instant $\mathbf{T}^{[t]}$. In this phase, the Eq. 13 must be solved, using one of the different methods, depending on the value assumed for the previously mentioned parameter $\alpha$, in Eq. 17. The result is a new thermal field $\mathbf{T}^{[t+\Delta t]}$. The main steps of the global thermomechanical algorithm are summarized in Table 1.

\section{Numerical examples}

In this section, four examples of frictionless and frictional thermal contact are presented. In order to demonstrate the accuracy of the algorithm and to highlight the influence of the IHTC on the predicted temperature, the first three examples are dedicated to a specific problem. They can be divided as frictional heat generation, influence of gap distance on heat flow, and influence of the contact pressure on the heat flow. The last example comprises all these problems. In all examples, the mechanical behavior of the deformable bodies is assumed perfectly elastic, in order to focus the analysis at the interface behavior. For the same reason, the heat exchanges for the environment, by convection and radiation, are neglected. Besides, all the examples use solid linear finite elements (8-node hexahedral), for the resolution of both problems, thermal and mechanical. The obstacles or tools are considered as rigid bodies, and their outer surfaces are modeled with Nagata patches [35, 36]. The parameter $\alpha$ in Eq. 17 is always set to a value of ( $\alpha=$ 1 ), which corresponds to an Euler backward time integration scheme.

\subsection{Frictional heating of a block}

The first example involves the frictional sliding of an elastic block over a fixed rigid surface and it was adapted from Wriggers and Miehe [48]. This example allows to predict the temperature rise due to the frictional heat generation, neglecting the heat lost to the rigid surface by contact. Thus, the only heat fluxes that are considered on the boundary surface are only due to frictional heat generation. The temperature evolution is evaluated for the deformable body (block), while the temperature of the rigid surface

Table 1 Global thermomechanical algorithm

1: Process input data.

2: Initialize variables for the current configuration $C^{[t]}$.

3: Increment time step by $\Delta t$.

4: Mechanical problem: Prediction phase.

4.1: Determine $\mathbf{u}^{[t+\Delta \text {, trial }]}$ and $\lambda^{[t+\Delta \text {, trial }]}$.

4.2: Correct the increment size $\Delta t$, with the $r_{\text {min }}$ strategy.

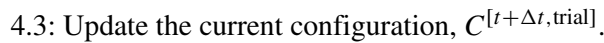

5: Mechanical problem: Correction phase.

5.1: Determine $\mathbf{u}^{[t+\Delta t]}$ and $\lambda^{[t+\Delta t]}$.

5.2: Update the current configuration, $C^{[t+\Delta t]}$.

6: Thermal problem.

6.1: Determine $\mathbf{T}^{[t+\Delta t]}$.

7: Go to point 2 and repeat the process until the total time is attained. 


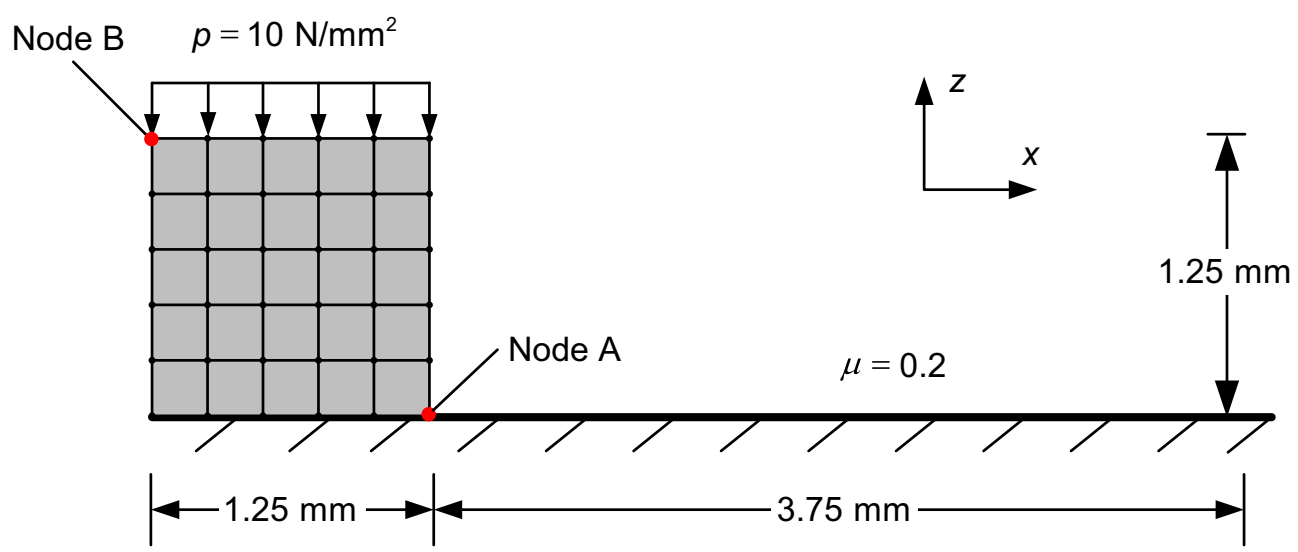

Fig. 5 Geometry setting of the frictional heating of a block problem and discretization

is assumed constant. The initial configuration of the problem and the finite element mesh adopted for the deformable body are presented in Fig. 5, assuming plane strain conditions. First, a pressure of $p=10 \mathrm{~N} / \mathrm{mm}^{2}$ is applied on the top of the block, followed by a prescribed horizontal displacement of $3.75 \mathrm{~mm}$ within $3.75 \times 10^{-3} \mathrm{~s}$, from the left to the right. The displacement is discretized into 100 time steps, as in the original example [48]. The friction is modeled by the Coulomb's law, with a friction coefficient of $\mu=0.2$. It is assumed that the energy dissipated by friction is totally converted into heat and the total amount of heat is equally partitioned between the body and the rigid surface. Thus, the parameters $\xi$ and $\beta$ on the Eq. 12 assume the value of 1 and 0.5 , respectively. The material properties are listed in Table 2 as well as the initial temperature condition.

The applied pressure and displacement of the block leads to the presence of a relative tangential contact force, which causes the heat generation. The nodal contact forces in the block, evaluated by the mechanical problem, are presented in Fig. 6, for two instants. Before imposing the horizontal displacement, the contact force vectors are symmetric (Fig. 6a), while during the sliding the maximum values of friction force are localized on the front nodes (Fig. 6b), leading to higher temperature due to the frictional sliding. The

Table 2 Material properties and initial conditions

\begin{tabular}{lll}
\hline Young's modulus & $E$ & $70,006 \mathrm{~N} / \mathrm{mm}^{2}$ \\
Poisson's ratio & $v$ & 0.3 \\
Density & $\rho$ & $2.7 \times 10^{-9} \mathrm{Ns}^{2} / \mathrm{mm}^{4}$ \\
Expansion coefficient & $\alpha$ & $23.8 \times 10^{-6}{ }^{\circ} \mathrm{C}^{-1}$ \\
Conductivity & $k$ & $150 \mathrm{Ns} /{ }^{\circ} \mathrm{C}$ \\
Capacity & $c$ & $0.9 \times 10^{9} \mathrm{~mm}^{2} / \mathrm{s}^{2}{ }^{\circ} \mathrm{C}$ \\
Reference temperature & $T_{r e f}$ & $0{ }^{\circ} \mathrm{C}$ \\
Initial temperature & $T_{i n i}$ & $0{ }^{\circ} \mathrm{C}$ \\
\hline
\end{tabular}

temperature distribution in the block is presented in Fig. 7, for three different instants during the sliding, namely displacements $u=1.275,2.55$, and $3.75 \mathrm{~mm}$. The maximum value of temperature is reached in node A (Fig. 5), despite
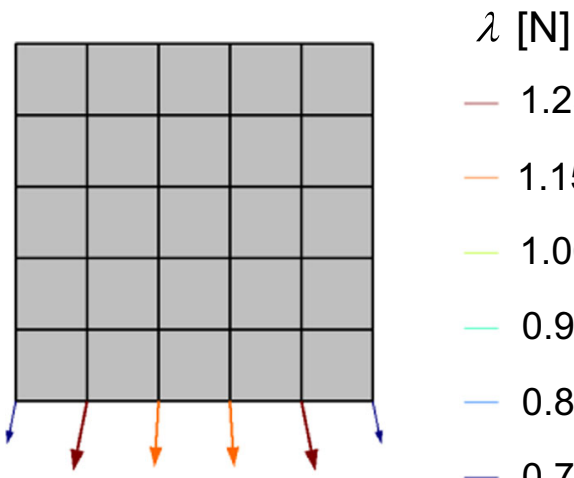

$-1.25$

$-1.15$

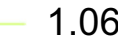

$-0.96$

$-0.86$

$-0.77$

(a)

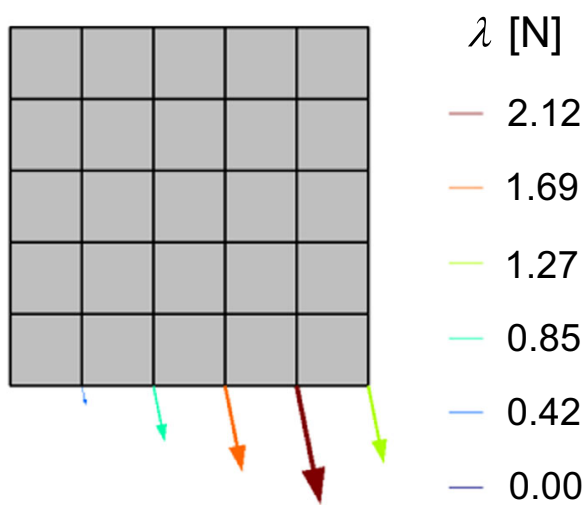

(b)

Fig. 6 Distribution of the contact forces: a instant immediately before the displacement imposition and $\mathbf{b}$ during the sliding for the time instant of $t=2.55 \times 10^{-3} \mathrm{~s}$ 
Fig. 7 Temperature distribution for the displacements: $u=1.25$, 2.5 , and $3.75 \mathrm{~mm}$

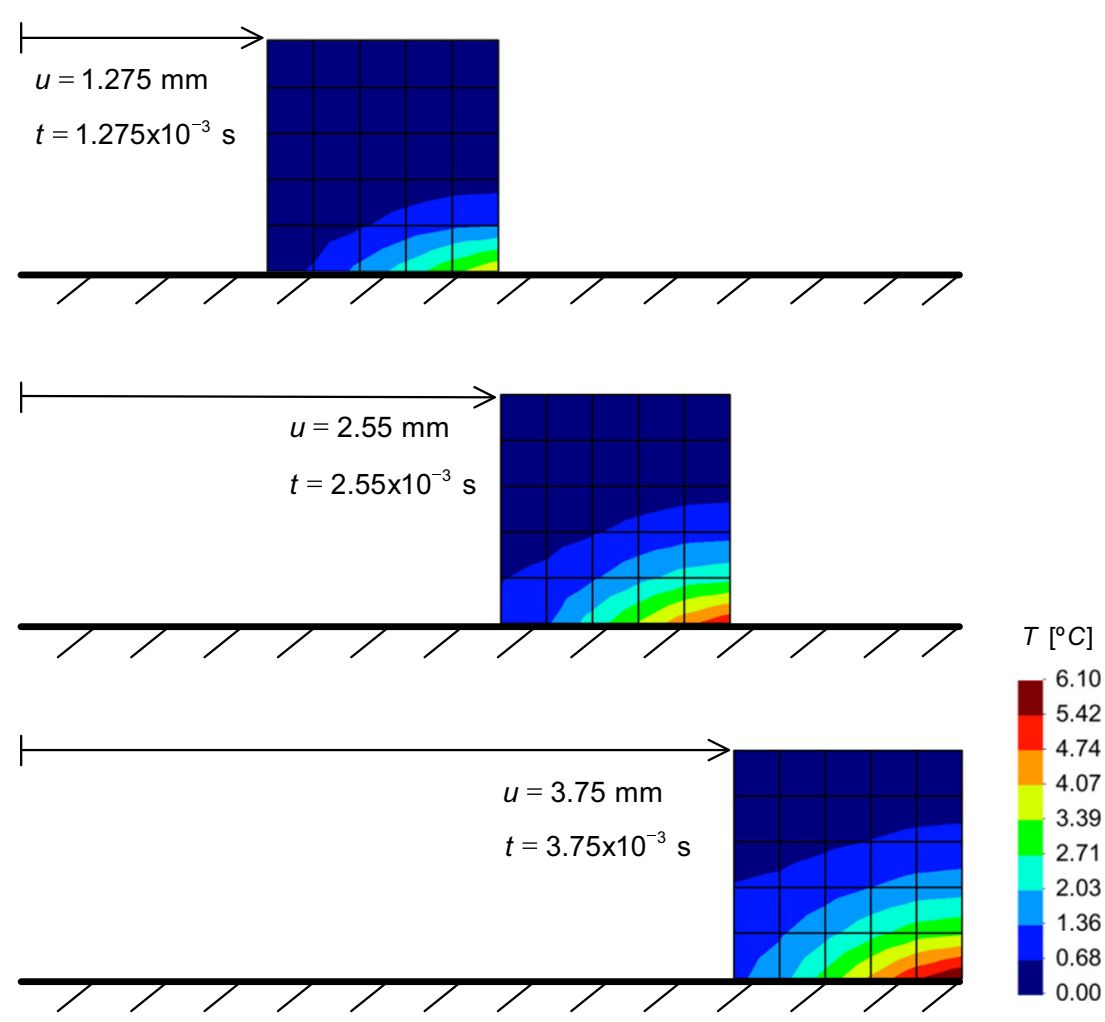

the maximum tangential force not being located on this node (Fig. 6b), as a result of the heat conduction phenomenon.

The numerical results concerning the temperature field can be compared with an analytical solution based on global energy check [48]. Therefore, in order to reach a homogeneous temperature for the block, it was kept stationary during $1 \mathrm{~s}$ without heat exchanges through the boundaries after heating by frictional sliding. The homogeneous temperature predicted by the finite element model is $1.234{ }^{\circ} \mathrm{C}$ and the temperature calculated analytically is $1.235^{\circ} \mathrm{C}$. Figure 8 presents the evolution of the temperature for node A and node B (Fig. 5), during the heating by frictional contact and subsequent temperature homogenisation. After non homogeneous heating, the temperature in both nodes tends quickly to the temperature provided by the analytical solution.

\subsection{Heat transfer between a sliding semi-sphere and a base}

This example involves the interfacial heat transfer between a semi-spherical shell and a parallelepiped base with an initial lower temperature. Since the mechanical contact between the bodies occurs in a single point, this example deals with the influence of the gap distance on the heat flux across the contact interface. Therefore, the IHTC value is considered dependent on the gap distance $\left(h_{\text {int }}\left(g_{n}\right)\right)$, as highlighted in
Eq. 11. The base geometry is $26 \times 10 \times 2 \mathrm{~mm}^{3}$ and its thermal properties are listed on Table 2, while the spherical shell presents a radius of $r=3 \mathrm{~mm}$. The base was discretized with 3120 hexahedral finite elements and the semi-spherical shell was discretized with 768 triangular Nagata patches (Fig. 9). The initial temperature of the base is $0{ }^{\circ} \mathrm{C}$, while the temperature of the semi-sphere is $40{ }^{\circ} \mathrm{C}$.

Friction is neglected in the mechanical contact. Accordingly, the heat fluxes are only due to the temperature gradient between the contacting surfaces of the semi-sphere and

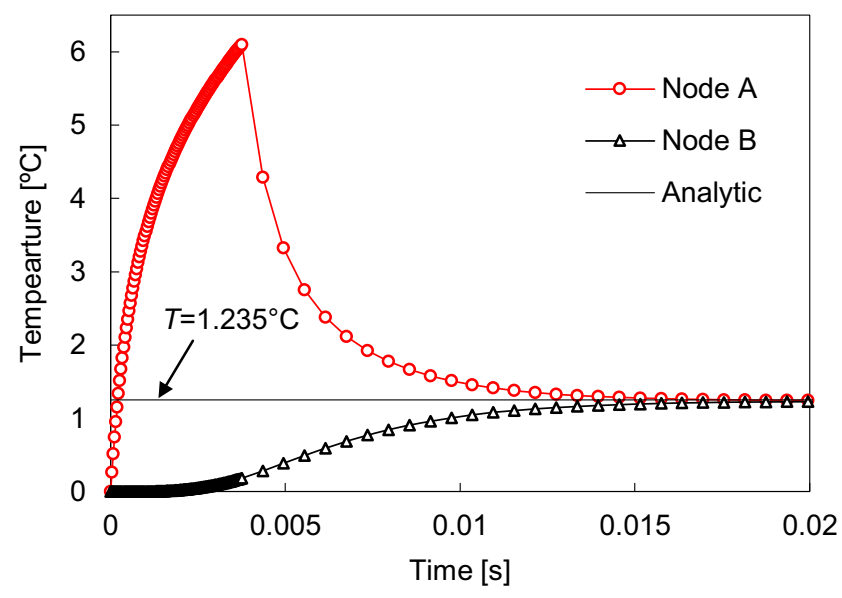

Fig. 8 Temperature evolution for the nodes A and B (represented in Fig. 5) 


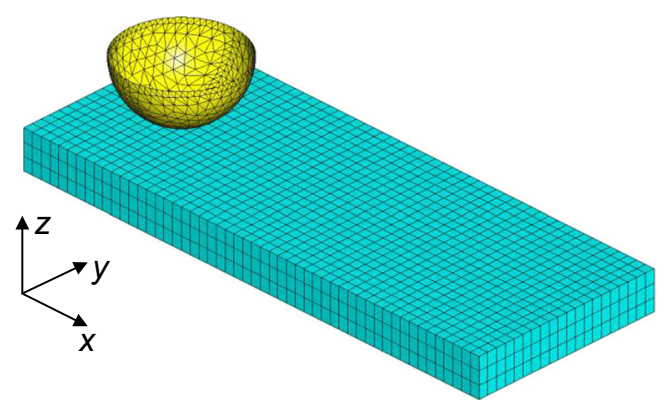

Fig. 9 Geometrical setting for problem 2 and respective finite element mesh

the parallelepiped base. The semi-sphere centre is initially located at $4 \mathrm{~mm}$ from the left hand of the base and is moved $18 \mathrm{~mm}$ in the $\mathrm{x}$-direction, within $18 \mathrm{~s}$ using a incremental displacement of $\Delta u=0.5 \mathrm{~mm}$. Four cases are compared, one with a constant value of IHTC and three with the IHTC dependent on the gap distance between the bodies, given by Eq. 11 using different values for the $m_{2}$. For the case of the constant IHTC, a value of $2500 \times 10^{-3} \mathrm{~N} /\left(\mathrm{smm}^{\circ} \mathrm{C}\right)$ was selected. The three sets of parameters selected for the variable IHTC definition are presented in Table 3. The evolution of the IHTC value with the gap distance is presented in Fig. 10, for the three sets of parameters presented in Table 3 , as well as for the constant IHTC.

The maximum value of gap distance for which the interfacial heat transfer occurs was restricted to $2 \mathrm{~mm}$ in the present example. The pattern of gap distance distribution, which defines the area where the heat flux occurs, is constant during the motion, due to the insignificant deformation of the base. Figure 11 presents the gap distance for each slave node of the base with projection, for the instant corresponding to a displacement of the semi-sphere of $u=9 \mathrm{~mm}$ and a time instant of $t=9 \mathrm{~s}$.

The temperature distribution on the base is presented in Fig. 12 for a displacement of the semi-sphere of $u=$ $9 \mathrm{~mm}$, considering the four cases of the IHTC. The temperature distribution presented in Fig. 12a considers a constant

Table 3 Set of parameter for example 2

\begin{tabular}{lll}
\hline Set 1 & $h_{\text {inf }}$ & $0 \mathrm{~N} /\left(\mathrm{smm}^{\circ} \mathrm{C}\right)$ \\
& $h_{\text {med }}$ & $2500 \times 10^{-3} \mathrm{~N} /\left(\mathrm{smm}^{\circ} \mathrm{C}\right)$ \\
& $m_{2}$ & 8 \\
Set 2 & $h_{\text {inf }}$ & $0 \mathrm{~N} /\left(\mathrm{smm}^{\circ} \mathrm{C}\right)$ \\
& $h_{\text {med }}$ & $2500 \times 10^{-3} \mathrm{~N} /\left(\mathrm{smm}^{\circ} \mathrm{C}\right)$ \\
& $m_{2}$ & 4 \\
Set 3 & $h_{\text {inf }}$ & $0 \mathrm{~N} /\left(\mathrm{smm}^{\circ} \mathrm{C}\right)$ \\
& $h_{\text {med }}$ & $2500 \times 10^{-3} \mathrm{~N} /\left(\mathrm{smm}^{\circ} \mathrm{C}\right)$ \\
& $m_{2}$ & 2
\end{tabular}

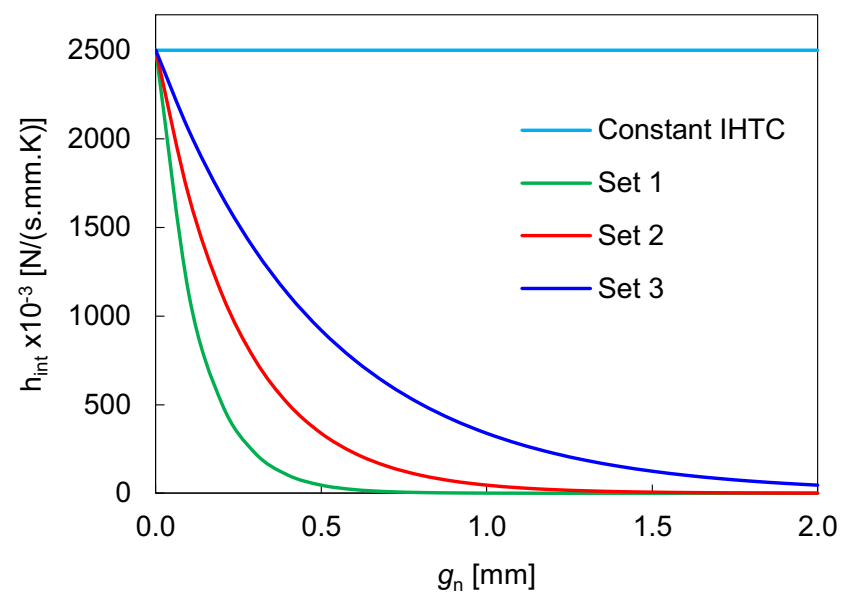

Fig. 10 Evolution of the IHTC with the gap distance (11), for the parameter sets presented in Table 3 and for the constant value of $2500 \times$ $10^{-3} \mathrm{~N} /\left(\mathrm{smm}^{\circ} \mathrm{C}\right)$

value for the IHTC, while the interfacial heat transfer occurs only with physical contact. On the other hand, the temperature distribution considering an IHTC dependent on the gap distance is presented in Fig. 12b-d for the parameter sets 1,2, and 3 listed in Table 3, respectively. The increase of temperature is lower using the constant value of IHTC (Fig. 12a), because the heat flux occurs only in a single contact point. On the other hand, assuming an IHTC dependent on the gap distance leads to higher temperatures, as shown in Fig. 12b-d, for lower $m_{2}$ values. In fact, the thermal energy transferred for the base is higher, since the conditions to define the area where heat transference occurs was amplified (Fig. 10). Figure 13 presents the temperature evolution for a node located in the middle of the top surface of the base. The trend for the temperature evolution is identical with a constant or variable IHTC, showing the influence of the zero gap instant. Moreover, the influence of the IHTC value is highlighted in the temperature increase, which is higher for the IHTC dependent of the gap distance due to the increase of the area where the heat flux arises.

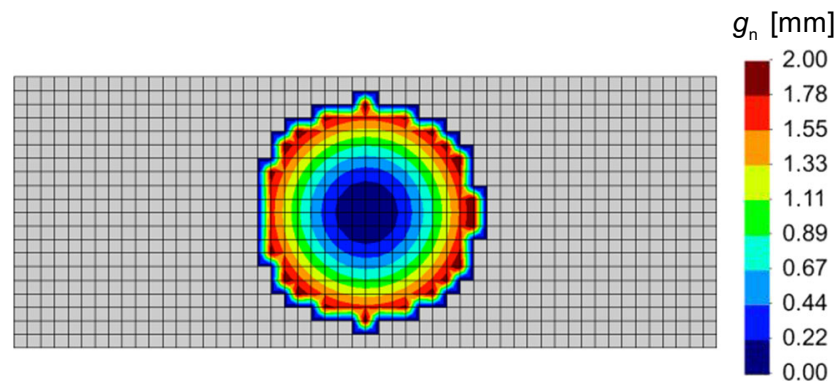

Fig. 11 Normal gap distance for the nodes with projection, for a displacement of $u=9 \mathrm{~mm}$ 


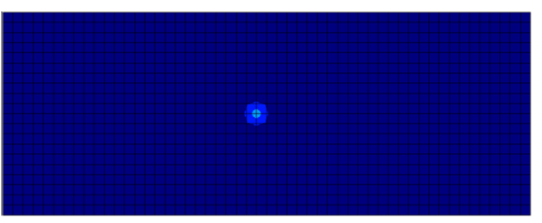

(a)

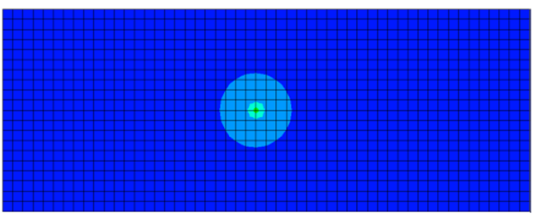

(b)

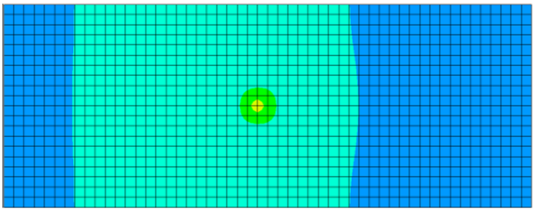

$T\left[{ }^{\circ} \mathrm{C}\right]$

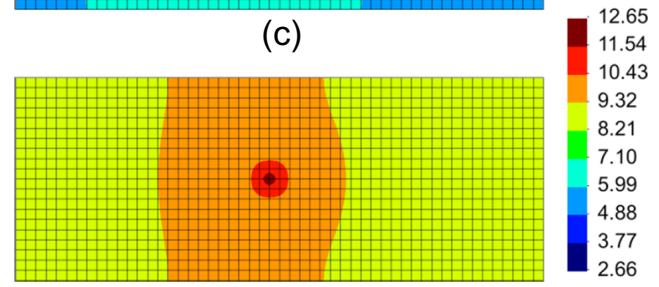

(d)

Fig. 12 Temperature distribution for a displacement of $u=9 \mathrm{~mm}$ : a IHTC not dependent on the gap distance. IHTC dependent on the gap distance: $\mathbf{b}$ set 1 , $\mathbf{c}$ set 2 , and $\mathbf{c}$ set 3 of Table 4

\subsection{Heating of a block with two warm plates}

This example highlights the influence of the contact pressure on the heat flux across the contact interface between a block and two heated plates. Figure 14 illustrates the geometry of the problem as well as the finite element mesh. The

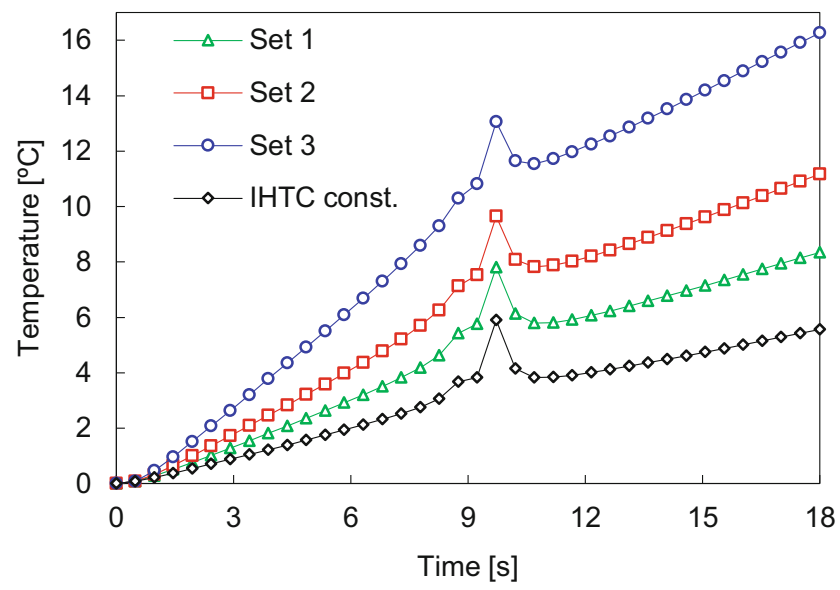

Fig. 13 Temperature evolution along the time for the node located on the center of the base top surface

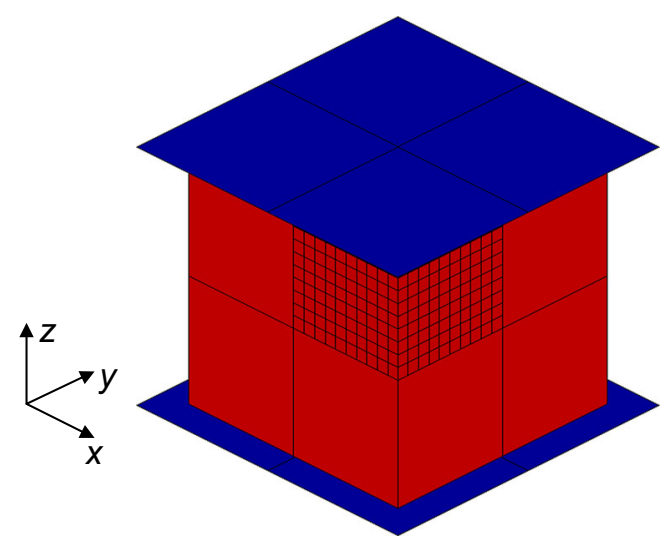

Fig. 14 Geometrical setting for heating a block with two warm plates and finite element mesh

block has dimensions of $40 \times 40 \times 40 \mathrm{~mm}^{3}$ and it has an initial temperature of $0{ }^{\circ} \mathrm{C}$, whereas the plates are at $40^{\circ} \mathrm{C}$. The heating of the block is carried out through contact with the two isothermal plates, assuming that the IHTC depends on the contact pressure (11). Due to the symmetry conditions, only an eight of the problem was simulated, as shown in Fig. 14. The block is discretized with a structured mesh of $10 \times 10 \times 10$ hexahedral finite elements and the plate is discretized with one quadrilateral Nagata patch. The material properties for the block are presented in Table 2.

In order to evaluate the influence of the contact pressure on the amount of heat flow to the block, two values of contact pressure were applied, namely 3 and $30 \mathrm{~N} / \mathrm{mm}^{2}$. Concerning the distribution of the IHTC as function of the contact pressure, Fig. 15 presents the selected evolution for the IHTC, given by Eq. 11 using the parameters presented in Table 4. The value of the IHTC for the pressure of $3 \mathrm{~N} / \mathrm{mm}^{2}$ is about $3278 \mathrm{~N} /\left(\mathrm{smm}^{\circ} \mathrm{C}\right)$, while for the pressure of $30 \mathrm{~N} / \mathrm{mm}^{2}$ is about $5351 \mathrm{~N} /\left(\mathrm{smm}^{\circ} \mathrm{C}\right)$, as highlighted

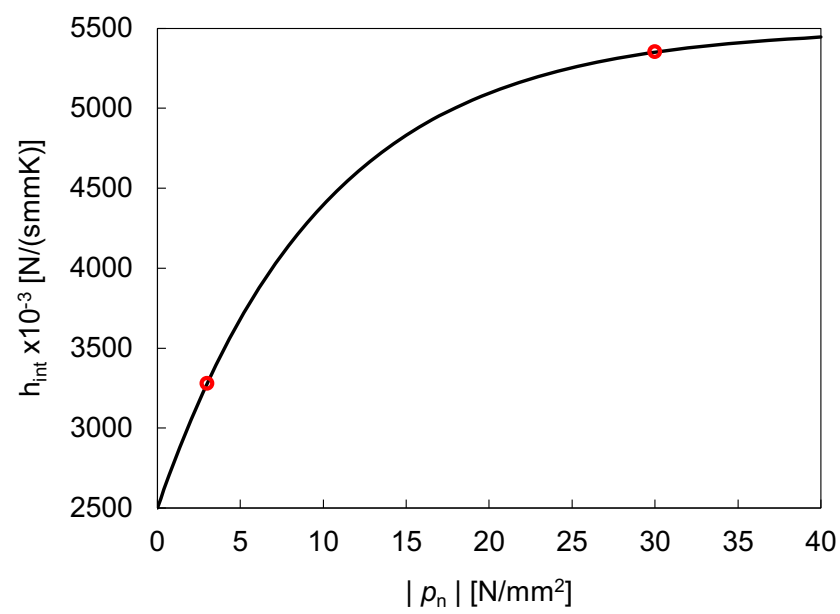

Fig. 15 Evolution of the IHTC with the contact pressure (11), for the parameters of Table 4 
Table 4 Set of parameters for example 3

\begin{tabular}{ll}
\hline$h_{\text {sup }}$ & $5500 \times 10^{-3} \mathrm{~N} /\left(\mathrm{smm}^{\circ} \mathrm{C}\right)$ \\
$h_{\text {med }}$ & $2500 \times 10^{-3} \mathrm{~N} /\left(\mathrm{smm}^{\circ} \mathrm{C}\right)$ \\
$m_{1}$ & 0.1 \\
\hline
\end{tabular}

in Fig. 15 (red dots). The total heating time is $60 \mathrm{~s}$ and the increment of time selected was $\Delta t=1.2 \mathrm{~s}$.

Figure 16a, b presents the temperature distribution in the first time increment, corresponding to $1.2 \mathrm{~s}$, for the pressure of 3 and $30 \mathrm{~N} / \mathrm{mm}^{2}$, respectively. The influence of the contact pressure on the temperature distribution is highlighted, namely in the maximum value attained, which arises in the contact interface. Therefore, the proposed model for the IHTC value, as function of the contact pressure, is able to predict different temperature distributions according to the contact conditions.

Figure 17 presents the evolution of the temperature for two nodes, one located in the top surface of the block (node 1) and the other situated $10 \mathrm{~mm}$ below the top surface (node 2). The positions of these nodes are presented in Fig. 16. The

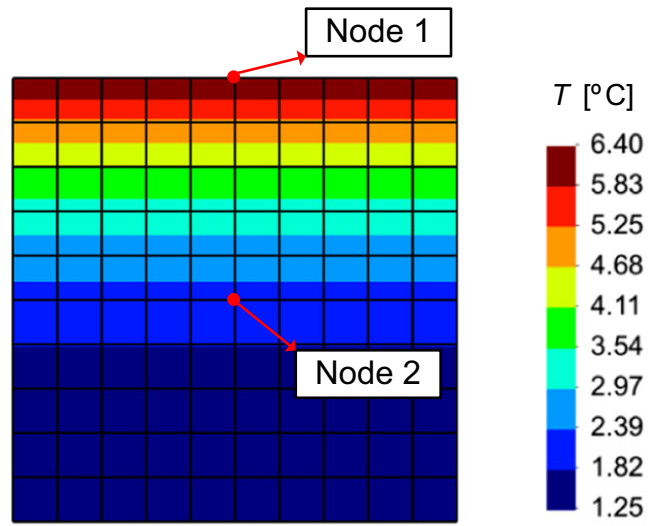

(a)

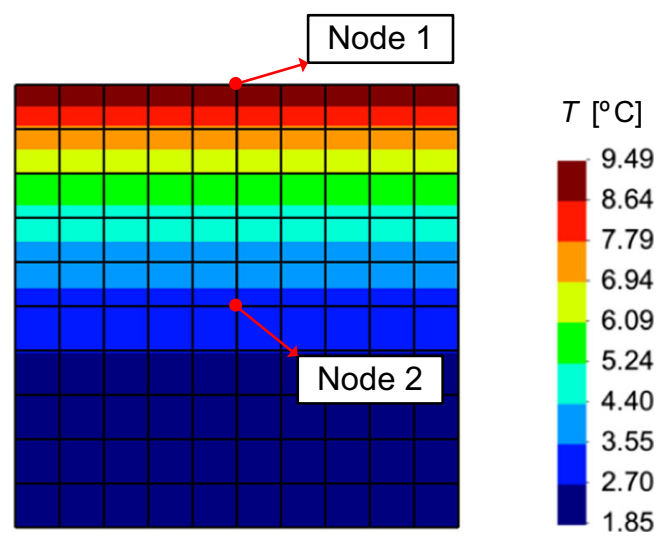

(b)

Fig. 16 Temperature distribution for the instant of $1.2 \mathrm{~s}$ : a pressure of $3 \mathrm{~N} / \mathrm{mm}^{2}$ and $\mathbf{b}$ pressure of $30 \mathrm{~N} / \mathrm{mm}^{2}$

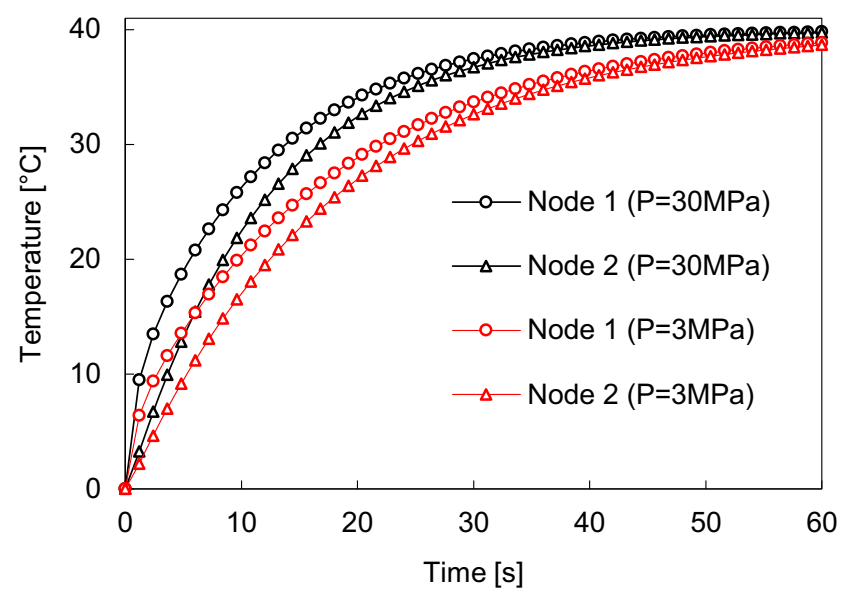

Fig. 17 Temperature evolution for two nodes. Node 1 situated on the top surface of the block and node 2 situated $5 \mathrm{~mm}$ below the top surface

red lines correspond to a pressure of $3 \mathrm{~N} / \mathrm{mm}^{2}$ and the black lines correspond to a pressure of $30 \mathrm{~N} / \mathrm{mm}^{2}$. The slop of the curves decreases with the temperature increase, because the thermal gradient in the contact interface is decreasing. Besides, for large values of heating time, the temperature difference between the selected nodes decreases, due to the heat conduction effect.

\subsection{Ironing with a heated cylindrical die}

This last example was designed to comprise the three aspects focused in the last three examples, the frictional heat generation and the influence of the gap distance and the contact pressure on the IHTC value. The problem comprises a rigid cylindrical shell sliding over a deformable parallelepiped base. Figure 18 illustrates the geometrical setting and the finite element mesh of the bodies. The parallelepiped base has dimensions of $34 \times 5 \times 10 \mathrm{~mm}^{3}$, while

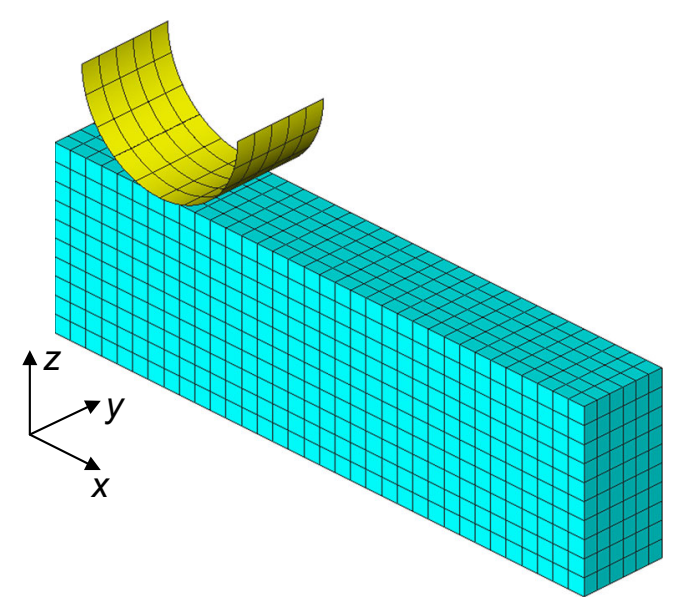

Fig. 18 Geometrial setting for ironing a deformable parallelepiped base and finite element mesh 
Table 5 Set of parameters for example 4

\begin{tabular}{ll}
\hline$h_{\text {sup }}$ & $5500 \times 10^{-3} \mathrm{~N} /\left(\mathrm{smm}^{\circ} \mathrm{C}\right)$ \\
$h_{\text {med }}$ & $2500 \times 10^{-3} \mathrm{~N} /\left(\mathrm{smm}^{\circ} \mathrm{C}\right)$ \\
$h_{\text {inf }}$ & $0 \mathrm{~N} /\left(\mathrm{smm}^{\circ} \mathrm{C}\right)$ \\
$m_{1}$ & 0.1 \\
$m_{2}$ & 2 \\
\hline
\end{tabular}

the cylindrical shell has a radius of $r=5 \mathrm{~mm}$. The parallelepiped base is discretized with 2400 finite elements, while the cylindrical shell is described by 50 quadrilateral Nagata patches. The material properties of the deformable body are listed in Table 2, except the Young's modulus, which was changed to $E=200 \mathrm{~N} / \mathrm{mm}^{2}$, in order to attain contact pressures in the same range of the last example. The temperature of the cylindrical shell is assumed constant $\left(60{ }^{\circ} \mathrm{C}\right)$, while the initial base temperature is $0{ }^{\circ} \mathrm{C}$. The centre of the cylindrical shell is initially located at $7 \mathrm{~mm}$ from the left hand of the base. First, a vertical displacement of $1 \mathrm{~mm}$ is prescribed to the cylindrical shell in the z-direction, followed by a horizontal displacement of $20 \mathrm{~mm}$ in the $\mathrm{x}$ direction. The vertical movement corresponds to the instant from 0 to $5 \mathrm{~s}$, which is discretized using $\Delta t=0.5 \mathrm{~s}$. On the other hand, the horizontal movement occurs from instant 5 to $20 \mathrm{~s}$, discretized in $\Delta t=0.4 \mathrm{~s}$.

In order to evaluate the influence of the contact pressure and the gap distance on the IHTC, two cases are compared. The IHTC value is defined as constant in the first case, i.e., independent of the contact pressure and the gap distance, adopting the value of $5500 \times 10^{-3} \mathrm{~N} /\left(\mathrm{smm}^{\circ} \mathrm{C}\right)$. In the second case, the IHTC value is described by Eq. 11, using the parameters presented in Table 5. Figure 19 presents the evolution of the IHTC based on the parameters of Table 5 . The heat generation by friction is considered in both cases. The friction is modeled by the Coulomb's law with a friction coefficient of $\mu=0.1$ and the parameters $\xi$ and $\beta$ on Eq. 12 assume the value of 1 and 0.5 , respectively. Figure 20

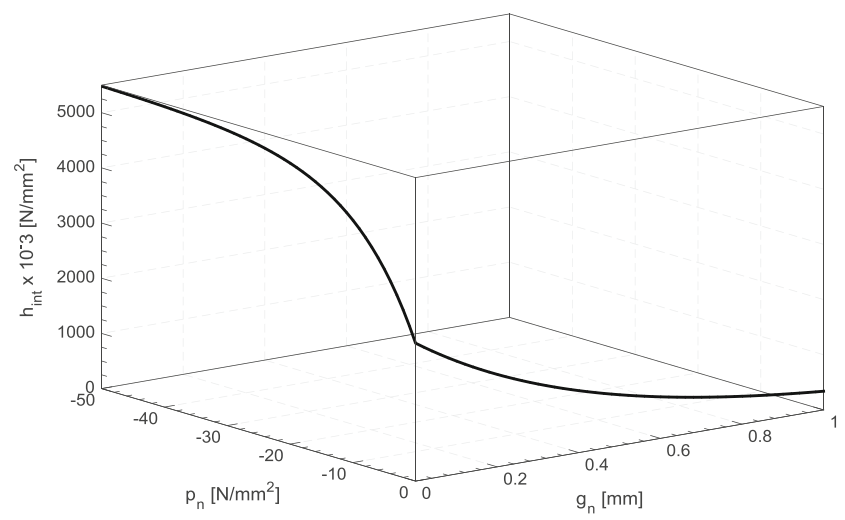

Fig. 19 Evolution of IHTC with the contact pressure and the gap distance (11), for the parameters of Table 5.

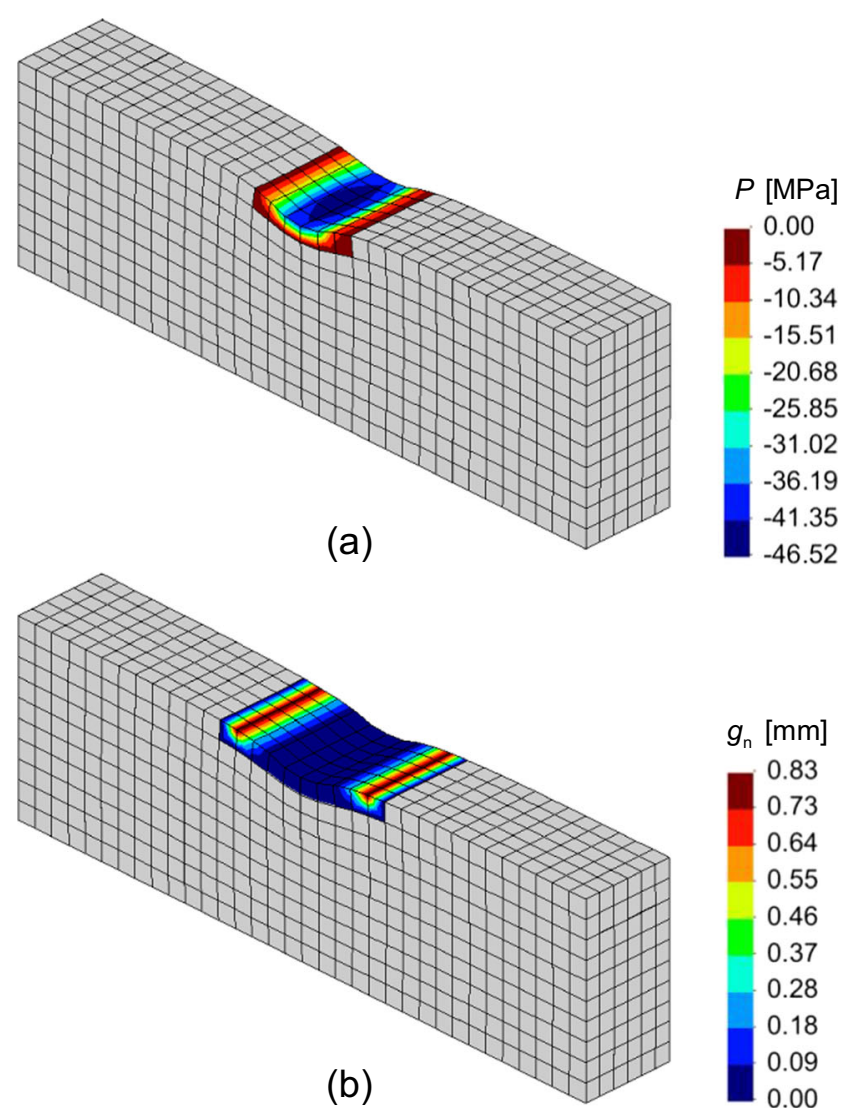

Fig. 20 Contact pressure and gap distance for the points with projection, instant of $15 \mathrm{~s}$

presents the contact pressure and the gap distance for each slave node, for the $15 \mathrm{~s}$ instant. These distributions remain almost unchanged during the entire sliding phase.

Figure 21 presents the temperature distribution for the two previously mentioned cases, at the instant $15 \mathrm{~s}$. The highest temperature value is attained for the case where the IHTC is described by Eq. 11 (see Fig. 21b). The influence of the gap distance on the IHTC has a dominant role in this situation, since it promotes an increase in the area for heat exchanges and it leads to an increase in the thermal energy transferred to the base. Moreover, the results of Fig. 21 show the importance of taking into account the gap distance and the contact pressure on the IHTC for an accurate prediction of the temperature distribution.

The temperature evolution is analyzed in two nodes located in the plane corresponding to half width of the base. The first node is located $7 \mathrm{~mm}$ from the left hand of the base and the second is located $17 \mathrm{~mm}$ from the left hand of the base (centre node). The positions of these nodes are represented in Fig. 21. Figure 22 presents the temperature evolution for these nodes. The black lines correspond to the IHTC constant value and the red lines correspond to a IHTC described by Eq. 11, with the parameters of Table 5 . The temperature is always lower for the constant IHTC. In 


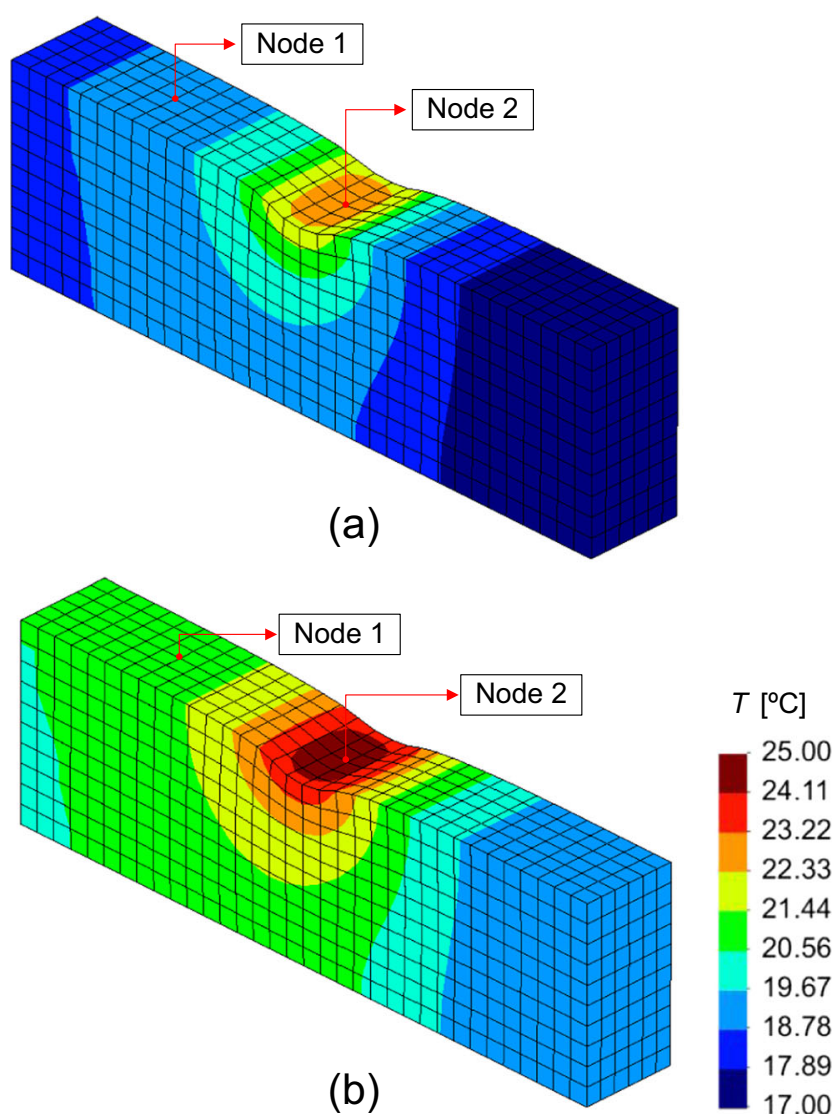

Fig. 21 Temperature distribution for the instant of $15 \mathrm{~s}$ : a IHTC constant b IHTC described by Eq. 11 and the parameters of Table 5

addition, oscillations in the temperature history are noticeable for the case of constant IHTC. These oscillations result from changes in the contact status (gap and contact), since when a node changes the contact status to gap, the heat flux imposed is zero. For the case of the IHTC described by the

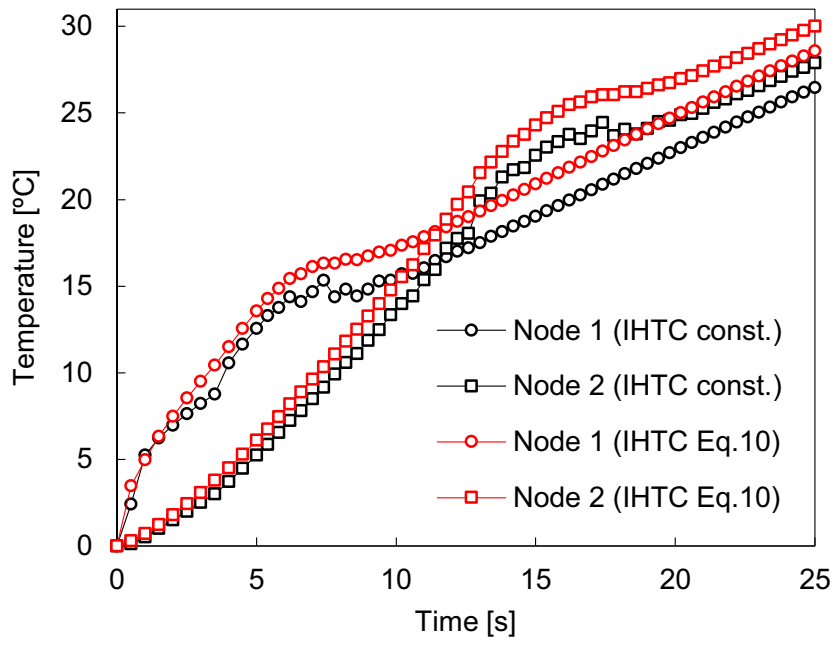

Fig. 22 Temperature evolution for two nodes located on the top surface proposed law, these oscillations are avoided, as a result of a smooth transition of the heat flux value.

\section{Conclusion}

This paper presents a finite element model developed for thermal contact analysis, which takes into account the interfacial heat transfer and the frictional heat generation. The interfacial heat transfer coefficient (IHTC) is described by a mathematical law inspired in experimental observations of the macro-contact analysis. It takes into account the contact pressure and the gap distance, providing a smooth transition between the two contact status (gap and contact). A staggered scheme was proposed to deal with the coupling of the thermomechanical problem, which consists in solving the mechanical problem for a previously calculated temperature, while the thermal problem is solved in the current configuration. Four numerical examples were used to validate the model and to demonstrate the efficiency of the proposed law. The temperature prediction due to frictional contact is presented in the first example, which is in good agreement with the analytical solution. The heat transfer through the contact interface is evaluated in the other two examples, highlighting the influence of the contact pressure and the gap distance on the IHTC value. The last example comprise the interfacial heat transfer and the frictional heat generation. With this example the importance of the proposed law for the smoothing of the transition between contact status (gap and contact) was highlighted. Thus, the proposed law is a promising solution to improve the accuracy of the numerical simulations involving interfacial heat transfer.

Acknowledgments The authors gratefully acknowledge the financial support of the Portuguese Foundation for Science and Technology (FCT) under the project PTDC/EMS-TEC/1805/2012 and by FEDER funds through the program COMPETE Programa Operacional Factores de Competitividade, under the project CENTRO-07-0224FEDER-002001 (MT4MOBI). The second author is also grateful to the FCT for the postdoctoral grant SFRH/BPD/101334/2014. The authors would like to thank Prof. A. Andrade-Campos for helpful contributions on the development of the finite element code presented in this work.

\section{References}

1. Adam L, Ponthot JP (2002) Numerical simulation of viscoplastic and frictional heating during finite deformation of metal. part i: theory. J Eng Mech 128(11):1215-1221. doi:10.1061/(ASCE)0733-9399(2002)128:11(1215)

2. Agelet de Saracibar C (1998) Numerical analysis of coupled thermomechanical frictional contact problems. Computational model and applications. Arch Comput Meth Eng 5(3):243-301. doi:10.1007/BF02897875 
3. Akar N, Azahin HM, Yalin N, Kocatepe K (2008) Experimental study on the effect of liquid metal superheat and casting height on interfacial heat transfer coefficient. Exp Heat Transfer 21(1):8398. doi:10.1080/08916150701647785

4. Alart P, Curnier A (1991) A mixed formulation for frictional contact problems prone to newton like solution methods. Comput Methods Appl Mech Eng 92(3):353-375. doi:10.1016/0045-7825(91)90022-X

5. Bai Q, Lin J, Zhan L, Dean T, Balint D, Zhang Z (2012) An efficient closed-form method for determining interfacial heat transfer coefficient in metal forming. Int J Mach Tools Manuf 56:102-110. doi:10.1016/j.ijmachtools.2011.12.005

6. Banjac M, Vencl A, Otović S (2014) Friction and wear processes-thermodynamic approach. Tribology in Industry 36 (4)

7. Bansal DG, Streator JL (2009) A method for obtaining the temperature distribution at the interface of sliding bodies. Wear 266(7-8):721-732. doi:10.1016/j.wear.2008.08.019

8. Bathe KJ (1996) Finite element procedures. Prentice-Hall, Englewood Cliffs

9. Beck JV (1970) Nonlinear estimation applied to the nonlinear inverse heat conduction problem. Int J Heat Mass Transfer 13(4):703-716. doi:10.1016/0017-9310(70)90044-X

10. Bhushan B (2000) Modern tribology handbook, Two Volume Set. Crc Press

11. Caron EJ, Daun KJ, Wells MA (2014) Experimental heat transfer coefficient measurements during hot forming die quenching of boron steel at high temperatures. Int $\mathrm{J}$ Heat Mass Transfer 71:396-404. doi:10.1016/j.ijheatmasstransfer.2013.12.039

12. Cervera M, Codina R, Galindo M (1996) On the computational efficiency and implementation of block-iterative algorithms for nonlinear coupled problems. Eng Comput 13(6):4-30. doi:10.1108/02644409610128382

13. Chang $\mathrm{Y}$, Tang $\mathrm{X}$, Zhao K, Hu P, Wu Y (2014) Investigation of the factors influencing the interfacial heat transfer coefficient in hot stamping. J Mater Process Technol. doi:10.1016/j.jmatprotec.2014.10.008

14. Chen Q, Li D (2005) A computational study of frictional heating and energy conversion during sliding processes. Wear 259(712):1382-1391. doi:10.1016/j.wear.2004.12.025. 15th International Conference on Wear of Materials

15. Conte M, Pinedo B, Igartua A (2014) Frictional heating calculation based on tailored experimental measurements. Tribol Int 74:1-6. doi:10.1016/j.triboint.2014.01.020

16. Dureja A, Pawaskar D, Seshu P, Sinha S, Sinha R (2015) Experimental determination of thermal contact conductance between pressure and calandria tubes of Indian pressurised heavy water reactors. Nucl Eng Des 284:60-66. doi:10.1016/j.nucengdes.2014.11.025

17. Golosnoy IO, Cipitria A, Clyne TW (2009) Heat transfer through plasma-sprayed thermal barrier coatings in gas turbines: a review of recent work. J Therm Spray Tech 18(5-6):809-821. doi:10.1007/s11666-009-9337-y

18. Hughes TJ (2012) The finite element method: linear static and dynamic finite element analysis. Courier Corporation

19. Ireman P, Klarbring A, Strömberg N (2002) Finite element algorithms for thermoelastic wear problems. Eur J Mech A Solids 21(3):423-440. doi:10.1016/S0997-7538(02)01208-1

20. Karbasian H, Tekkaya A (2010) A review on hot stamping. J Mater Process Technol 210(15):2103-2118. doi:10.1016/j.jmatprotec.2010.07.019

21. Kaya S (2015) Nonisothermal warm deep drawing of ss304: fe modeling and experiments using servo press. Int J Adv Manuf Technol:1-10. doi:10.1007/s00170-015-7620-2
22. Kennedy FE, Lu Y, Baker I (2015) Contact temperatures and their influence on wear during pin-on-disk tribotesting. Tribol Int 82:534-542. doi:10.1016/j.triboint.2013.10.022

23. Kleiner M, Geiger M, Klaus A (2003) Manufacturing of lightweight components by metal forming. CIRP Ann Manuf Technol 52(2):521-542. doi:10.1016/S0007-8506(07)60202-9

24. Klocke F, Trauth D, Shirobokov A, Mattfeld P (2015) Fe-analysis and in situ visualization of pressure-, slip-rate-, and temperaturedependent coefficients of friction for advanced sheet metal forming: development of a novel coupled user subroutine for shell and continuum discretization. Int J Adv Manuf Technol:1-14. doi:10.1007/s00170-015-7184-1

25. Laurent H, Cor J, Manach $\mathrm{P}$, Oliveira M, Menezes L (2015) Experimental and numerical studies on the warm deep drawing of an al-mg alloy. Int J Mech Sci 93:59-72. doi:10.1016/j.ijmecsci.2015.01.009

26. Lee SL, Ou CR (2001) Gap formation and interfacial heat transfer between thermoelastic bodies in imperfect contact. J Heat Transf 123(2):205. doi:10.1115/1.1338133

27. Liu X, Ji K, El Fakir O, Liu J, Zhang Q, Wang L (2015) Determination of the interfacial heat transfer coefficient in the hot stamping of AA7075. In: MATEC Web of conferences, EDP sciences, vol 21, p 5003

28. Madhusudana CV (1996) Thermal contact conductance. Springer

29. Martins JMP, Alves JL, Neto DM, Oliveira MC, Menezes LF (2016) Numerical analysis of different heating systems for warm sheet metal forming. Int J Adv Manuf Technol 83(5):897-909. doi:10.1007/s00170-015-7618-9

30. Menezes LF, Teodosiu C (2000) Three-dimensional numerical simulation of the deep-drawing process using solid finite elements. J Mater Process Technol 97(1-3):100-106. doi:10.1016/S0924-0136(99)00345-3

31. Merchant H, Murty G, Bahadur S, Dwivedi L, Mehrotra Y (1973) Hardness-temperature relationships in metals. J Mater Sci 8(3):437-442. doi:10.1007/BF00550166

32. Merklein M, Lechler J, Stoehr T (2009) Investigations on the thermal behavior of ultra high strength boron manganese steels within hot stamping. Int J Mater Form 2(1):259-262. doi:10.1007/s12289-009-0505-x

33. Merklein M, Wieland M, Lechner M, Bruschi S, Ghiotti A (2015) Hot stamping of boron steel sheets with tailored properties: a review. J Mater Process Technol. doi:10.1016/j.jmatprotec.2015.09.023

34. Miki B (1974) Thermal contact conductance; theoretical considerations. Int $\mathbf{J}$ Heat Mass Transfer 17(2):205-214. doi:10.1016/0017-9310(74)90082-9

35. Neto DM, Oliveira MC, Menezes LF, Alves JL (2013) Nagata patch interpolation using surface normal vectors evaluated from the IGES file. Finite Elem Anal Des 72:35-46. doi:10.1016/j.finel.2013.03.004

36. Neto DM, Oliveira MC, Menezes LF, Alves JL (2014) Applying Nagata patches to smooth discretized surfaces used in $3 \mathrm{~d}$ frictional contact problems. Comput Methods Appl Mech Eng 271:296320. doi:10.1016/j.cma.2013.12.008

37. Norouzifard V, Hamedi M (2014) A three-dimensional heat conduction inverse procedure to investigate tool-chip thermal interaction in machining process. Int $\mathrm{J}$ Adv Manuf Technol 74(912):1637-1648. doi:10.1007/s00170-014-6119-6

38. Oancea VG, Laursen TA (1997) A finite element formulation of thermomechanical rate-dependent frictional sliding. Int J Numer Methods Eng 40(23):4275-4311. doi:10.1002/(SICI)1097-0207 (19971215)40:23<4275::AID-NME257>3.0.CO;2-K

39. Oliveira MC, Menezes LF (2004) Automatic correction of the time step in implicit simulations of the stamping process. Finite Elem Anal Des 40(13):1995-2010. doi:10.1016/j.finel.2004.01.009 
40. Oliveira MC, Alves JL, Menezes LF (2008) Algorithms and strategies for treatment of large deformation frictional contact in the numerical simulation of deep drawing process. Arch Comput Meth Eng 15:113-162. doi:10.1007/s11831-008-9018-x

41. Pantuso D, Bathe KJ, Bouzinov PA (2000) A finite element procedure for the analysis of thermo-mechanical solids in contact. Comput Struct 75(6):551-573. doi:10.1016/S0045-7949(99)00212-6

42. Pereira MP, Rolfe BF (2014) Temperature conditions during cold sheet metal stamping. J Mater Process Technol 214(8):1749-1758. doi:10.1016/j.jmatprotec.2014.03.020

43. Rodrigues JMC, Martins PAF (2002) Finite element modelling of the initial stages of a hot forging cycle. Finite Elem Anal Des 38(3):295-305. doi:10.1016/S0168-874X(01)00065-8

44. Smith E, Arnell R (2014) The prediction of frictional temperature increases in dry, sliding contacts between different materials. Tribol Lett 55(2):315-328. doi:10.1007/s11249-014-0359-3

45. Tariq A, Asif M (2016) Experimental investigation of thermal contact conductance for nominally flat metallic contact. Heat Mass Transf 52(2):291-307. doi:10.1007/s00231-015-1551-1

46. Toros S, Kacar I (2008) Review of warm forming of aluminummagnesium alloys. J Mater Process Technol 207(1-3):1-12. doi:10.1016/j.jmatprotec.2008.03.057

47. Wriggers P (2006) Computational contact mechanics, vol 30167. Springer

48. Wriggers P, Miehe C (1994) Contact constraints within coupled thermomechanical analysis-a finite element model. Comput Methods Appl Mech Eng 113(3-4):301-319. doi:10.1016/0045-7825(94)90051-5
49. Xing H, Makinouchi A (2002) Fe modeling of thermoelasto-plastic finite deformation and its application in sheet warm forming. Eng Comput 19(4):392-410. doi: $10.1108 / 02644400210430172$

50. Xu R, Xu L (2005) An experimental investigation of thermal contact conductance of stainless steel at low temperatures. Cryogenics 45(10-11):694-704. doi:10.1016/j.cryogenics.2005.09.002

51. Yamada Y, Yoshimura N, Sakurai T (1968) Plastic stress-strain matrix and its application for the solution of elastic-plastic problems by the finite element method. Int J Mech Sci 10(5):343-354. doi:10.1016/0020-7403(68)90001-5

52. Yevtushenko A, Kuciej M, Yevtushenko O (2015) Modelling of the frictional heating in brake system with thermal resistance on a contact surface and convective cooling on a free surface of a pad. Int J Heat Mass Transfer 81:915-923. doi:10.1016/j.ijheatmasstransfer.2014.11.014

53. Yovanovich M (1982) Thermal contact correlations. AIAA paper 81:83-95

54. Yovanovich M (2004) Four decades of research on thermal contact, gap, and joint resistances in microelectronics - achievement award. The Ninth Intersociety Conference on Thermal and Thermomechanical Phenomena In Electronic Systems (IEEE Cat No04CH37543) 2(2):182-206. doi:10.1109/ITHERM.2004.1318237

55. Zhao K, Wang B, Chang Y, Tang X, Yan J (2015) Comparison of the methods for calculating the interfacial heat transfer coefficient in hot stamping. Appl Therm Eng 79:17-26. doi:10.1016/j.applthermaleng.2015.01.018 